\title{
Up-to-date on mortality in COPD - report from the OLIN COPD study
}

Anne Lindberg ${ }^{1,2,3^{*}}$, Lars-Gunnar Larsson ${ }^{2,3}$, Hana Muellerova ${ }^{4}$, Eva Rönmark ${ }^{2,5}$ and Bo Lundbäck 2,6

\begin{abstract}
Background: The poor recognition and related underdiagnosis of COPD contributes to an underestimation of mortality in subjects with COPD. Data derived from population studies can advance our understanding of the true burden of COPD. The objective of this report was to evaluate the impact of COPD on mortality and its predictors in a cohort of subjects with and without COPD recruited during the twenty first century.

Methods: All subjects with COPD $(n=993)$ defined according to the GOLD spirometric criteria, $F E V / F V C<0.70$, and gender- and age-matched subjects without airway obstruction, non-COPD ( $\mathrm{n}=993)$, were identified in a clinical follow-up survey of the Obstructive Lung Disease in Northern Sweden (OLIN) Studies cohorts in 2002-2004. Mortality was observed until the end of year 2007. Baseline data from examination at recruitment were used in the risk factor analyses; age, smoking status, lung function ( $\mathrm{FEV}_{1} \%$ predicted) and reported heart disease.

Results: The mortality was significantly higher among subjects with COPD, 10.9\%, compared to subjects without COPD, 5.8\% ( $p$ < 0.001). Mortality was associated with higher age, being a current smoker, male gender, and COPD. Replacing COPD with $\mathrm{FEV}_{1} \%$ predicted in the multivariate model resulted in the decreasing level of $\mathrm{FEV}_{1}$ being a significant risk factor for death, while heart disease was not a significant risk factor for death in any of the models.
\end{abstract}

Conclusions: In this cohort COPD and decreased FEV ${ }_{1}$ were significant risk factors for death when adjusted for age, gender, smoking habits and reported heart disease.

\section{Background}

Chronic Obstructive Pulmonary Disease (COPD) is recognized as a major public health problem with an increasing morbidity and mortality. It has been forecasted that COPD will be ranked the fourth burden of disease worldwide by year 2030 [1]. The prevalence of COPD is most often reported in the range of $6-10 \%$ of the total adult population [2], it is strongly correlated to smoking and age, and about $50 \%$ of elderly smokers fulfil the spirometric criteria of COPD [3]. Population studies have shown that a large majority of COPD patients have mildto-moderate disease [4].

The underdiagnosis of COPD is well-known. Only about a third of all cases with COPD have been recognized by the health care [3-6], and the proportion of undiagnosed cases decreases with increasing disease severity [4]. Most reports on mortality in COPD are

\footnotetext{
* Correspondence: anne.lindberg@nll.se

'Department of Public Health and Clinical Medicine, Division of Medicine, Umeå University, SE-901 85 Umeå, Sweden

Full list of author information is available at the end of the article
}

based on death certificates and hence, due to the underdiagnosis, the true impact of COPD on mortality is probably greatly underestimated. There are only few reports on mortality in COPD based on population studies. In a follow-up over up to 22 years of a large general population cohort in the USA, the NHANES I recruited 197175 follow-up in 1992 included totally 923 cases of COPD. The overall mortality in COPD was $44 \%$ and in severe COPD 71\%. Subjects with mild, moderate and severe COPD, and subjects with restrictive lung function impairment, had an increased risk for death [7]. There is a 30-year follow up of a large population sample from southern Sweden, both smokers and non-smokers with COPD had a significantly increased risk for death [8]. The first cohort of the Obstructive Lung Disease in Northern Sweden (OLIN) studies, was recruited in 198586 , and in a recently published 20-year follow-up an overall mortality of $54 \%$ in subjects with COPD was reported, while the mortality in severe and very severe COPD at entry was $81 \%$ [9].

\section{Biomed Central}


Irrespective of COPD, decline in lung function, expressed as $\mathrm{FEV}_{1}$, is known to predict death $[10,11]$. Reduced $\mathrm{FEV}_{1}$ has also been reported to be a marker of cardiovascular death [12]. However, due to the underdiagnosis and lack of longitudinal epidemiological data, the present impact of COPD identified through spirometric screening in the general population on mortality considering the influence of other factors such as cardiovascular co-morbidity has been ill-described.

Within the OLIN studies, cross-sectional and longitudinal data on respiratory diseases, including lung function, have been collected in several cohorts recruited from the general population at different occasions ever since $1985[3,4,9,13,14]$. Previously recruited adult OLINcohorts were invited to a clinical follow-up in 2002-2004, and from the participants all subjects with COPD were identified together with age and gender matched subjects without airway obstruction [15]. The aim of the present paper is to report overall mortality in this cohort based on mortality data collected up to the end of 2007, and to evaluate the impact of COPD, level of $\mathrm{FEV}_{1}$, gender, smoking habits and heart disease on mortality.

\section{Methods}

\section{Study design and Study population}

The recruitment of the study cohort and the study design has been reported previously [15]. In 2002-2004 four previously identified population based adult OLIN cohort (one from the eighties and three from the nineties) were invited to re-examination including structured interview and spirometry. When the examinations were completed all subjects with COPD according to The Global Initiative for Chronic Obstructive Lung Disease (GOLD) spirometric criteria [16], $\mathrm{FEV}_{1} / \mathrm{FVC}<0.70$, were identified ( $\mathrm{n}=$ 993) together with an age- and gender matched reference sample with non-obstructive lung function. This cohort, all together 1986 subjects (1084 men; 902 women) has since 2005 been invited to yearly examinations including lung function testing and a structured interview. The study was approved by the Regional Ethics Committee at University Hospital of Northern Sweden and Umeå University.

Data collected in 2002-2004 were used for baseline characteristics. The observation time is from the date of examination at recruitment until the end of year 2007, and the mean follow-up time can be approximated to four years. Mortality data during the period, including date of death, were collected from the national mortality register.

\section{Baseline measurements \\ Structured interview}

A previously validated questionnaire was administered via a structured interview $[4,13,14]$. Smoking habits were classified into the following groups: non-smokers, ex-smokers (stopped at least one year before the baseline visit) and current smokers. The variable theart disease' includes self-reported angina pectoris, previous coronary artery bypass surgery, previous percutaneous coronary intervention, myocardial infarction or heart failure.

\section{Spirometry}

The lung function tests were performed using a dry spirometer, Mijnhardt Vicatest 5 by following the ATS guidelines [17]. Vital capacity (VC) was defined as the best value of forced vital capacity (FVC) and slow vital capacity (SVC). A reversibility test was performed when the ratio of $\mathrm{FEV}_{1} / \mathrm{VC}$ was $<70 \%$ or if $\mathrm{FEV}_{1}$ was $<90 \%$ of predicted value. The Swedish normal values by Berglund et al were used [18]. When calculating the $\mathrm{FEV}_{1} / \mathrm{VC}$ ratio and defining the severity of COPD, the largest value of $\mathrm{FEV}_{1}$ as well as of $\mathrm{VC}$ was used.

\section{Body Mass Index}

Weight and height were recorded before the lung function test. Body Mass Index (BMI) was calculated: weight (kg)/ (height $(\mathrm{m})$ ")height $(\mathrm{m}))$ and was classified into normal (range $20-<25$ ), underweight $(<20)$, overweight (range $25-<30)$ and obesity $(\geq 30)$.

\section{Classification of COPD}

Spirometric classification of COPD according to GOLD, $\mathrm{FEV}_{1} / \mathrm{VC}<0.7$, was used. The classification of severity of COPD includes for stages based on $\mathrm{FEV}_{1} \%$ predicted.

Stage I FEV $1 \geq 80 \%$ predicted

Stage II $\mathrm{FEV}_{1} \geq 50$ and $<80 \%$ predicted

Stage III FEV $1 \geq 30$ and $<50 \%$ predicted

Stage IV $\mathrm{FEV}_{1}<30 \%$ predicted

\section{Statistical analysis}

Statistical calculations were made using the Statistical Package for the Social Sciences (SPSS) software version PASW 18.0 and Microsoft Excel 2007. The sample comprised of six age groups. Crude mortality rates based on data collected by the end of 2007 were analysed by gender, disease status (COPD or non-COPD), and selected baseline descriptors (smoking habits, BMI and heart disease). The chi-squared test was used for bi-variate comparisons and to test for trends. A p-value of $<0.05$ was regarded as significant. The hazard function of death, which describes the momentary risk, was estimated by use of Poisson regression depending on several variables. The follow-up period of each individual was divided into intervals of the length 0.1 years, when the contribution to the log likelihood function was calculated. The variables age and observation time was updated at each interval. For each risk variable of death, we calculated the hazard ratio (HR) of an increase of 1 unit and the corresponding 95\% confidence interval (CI). Three different models were studied 
including the following covariates: [1] age, observation time, gender, heart disease and disease status (COPD or non-COPD) [2] age, observation time, gender, disease status (COPD or non-COPD), heart disease, and $\mathrm{FEV}_{1}$ percent predicted, [3] age, observation time, gender, heart disease, and $\mathrm{FEV}_{1}$ percent predicted. For the models [1] and [3] analyses were also done including the variable smoking habits categorized as non-smoker, ex-smoker and smoker. A possible interaction between COPD and heart disease was tested in model 1 and an interaction between heart disease and $\mathrm{FEV}_{1}$ in the later models. Multivariable analyses were also conducted in models including the covariates BMI and smoking categories. Furthermore, we used a Poisson regression model including spline functions of $\mathrm{FEV}_{1}$, which allowed the hazard function to vary with a greater freedom and still correspond to a smooth curve. A simple model includes just one coefficient of $\mathrm{FEV}_{1}$ and that restrict the shape of the curve.

\section{Results}

\section{Study population}

Baseline characteristics of the study population at recruitment are shown in table 1 . All together, $36.2 \%$ of the subjects were non-smokers, $40.5 \%$ ex-smokers and 23.3\% current smokers. There were more smokers and fewer non-smokers in subjects with COPD compared to in non-COPD. The prevalence of self-reported heart disease was similar in COPD and non-COPD ( $\mathrm{p}=0.429)$. At recruitment the distribution by disease severity among subjects with COPD was $52.2 \%, 40.3 \%, 6.1 \%$, and $1.4 \%$, in GOLD stages I, II, III, and IV respectively.

Table 1 Study population, basic characteristics at the recruitment (2002-2004)

\begin{tabular}{llcc}
\hline Category & Variable & $\begin{array}{c}\text { COPD } \\
(\mathbf{n}=\mathbf{9 9 3})\end{array}$ & $\begin{array}{c}\text { No COPD } \\
(\mathbf{n}=\mathbf{9 9 3})\end{array}$ \\
\hline Gender (n) & Men & 543 & 541 \\
& Women & 450 & 452 \\
Age group, year of birth (n) & -1920 & 113 & 113 \\
& $1921-30$ & 146 & 147 \\
& $1931-40$ & 374 & 358 \\
& $1941-50$ & 267 & 282 \\
& $1951-60$ & 73 & 73 \\
Smoking (\%) & $1961-$ & 20 & 20 \\
& Non smoker & 24.1 & 47.9 \\
BMI (\%) & Ex smoker & 41.5 & 39.6 \\
& Smoker & 34.4 & 12.6 \\
& $<20$ & 3.9 & 1.6 \\
& $20-<25$ & 40.8 & 35.6 \\
Heart disease (\%) & $25-<30$ & 39.9 & 46.5 \\
\hline
\end{tabular}

\section{Mortality}

In total, 166 subjects, $8.4 \%$ (9.6\% men; $6.9 \%$ women, $\mathrm{p}=$ $0.029)$, had died until the end of 2007. Crude mortality data are shown in table 2 . The mortality was significantly higher among subjects with COPD, 10.9\% ( $\mathrm{n}=$ $108)$, compared to non-COPD subjects, $5.8 \%(\mathrm{n}=58)(\mathrm{p}$ $<0.001)$. No one had died in the youngest age group (born after 1961) but thereafter the mortality increased by increasing age both among subjects with and without COPD. Comparing COPD and non-COPD, the mortality was significantly higher among subjects with COPD in the three oldest age groups (born 1920 and before, 1921-1930 and 1931-1940). In smokers and ex-smokers, in subjects with BMI $>25$, and among those without concomitant heart disease, the mortality was significantly higher in subjects with COPD as compared to non-COPD. There was no significant difference in mortality between the COPD and non-COPD groups among non-smokers, subjects with underweight or normal weight (BMI $<20$ or BMI 20-25), and among subjects with reported heart disease.

\section{Analyses of risk factors for death}

In a multivariate model, COPD was a significant risk factor for death (HR 2.06, CI 1.49-2.85), and so was increasing age (HR 1.08, CI 1.07-1.10), male gender (HR 1.52, CI 1.10-2.10) and heart disease (HR 1.43, CI 1.012.02 ). When the variable smoking habits was added to the model, heart disease did not reach statistical significance, but close to (HR 1.42, CI 1.00-2.01) (table 3). BMI did not contribute significantly and ex-smoker did not significantly differ for non-smoker (not shown in tables). No significant interaction was found between heart disease and COPD or between $\mathrm{FEV}_{1}$ and heart disease, thus COPD was a significant risk factor for death irrespectively of reported heart disease at start of the observation period. Nor was there any significant interaction between COPD and smoking, i.e. COPD was associated with an increased mortality independent if smoking or not. In a model including both COPD and $\mathrm{FEV}_{1}, \mathrm{COPD}$ lost its significance as a risk factor for death in the presence of $\mathrm{FEV}_{1}$ in the statistical model. Figure 1 illustrates an example of the hazard function of death in relation to $\mathrm{FEV}_{1}$ in a 70 year old man after an observation time of two years. The model including a spline function indicates that the effect of $\mathrm{FEV}_{1}$ on mortality is more outstanding in subjects with $\mathrm{FEV}_{1}<50 \%$ of predicted values than what can be shown by using a simpler model. Using $\mathrm{FEV}_{1}$ instead of COPD in the multivariate model, decrease in level of $\mathrm{FEV}_{1}$ at baseline was an independent significant risk factor for death together with increasing age, male gender and current smoking while heart disease did not reach statistical significance (table 4). 
Table 2 Crude mortality in percent among subjects with COPD and controls (FEV 1 VC $<0.70$ and FEV 1 VC $>0.70$, respectively), by gender, age-group (year of birth), smoking habits, BMI and reported heart disease

\begin{tabular}{|c|c|c|c|c|c|c|}
\hline Category & Variable & COPD $(n=993)$ & p-value ${ }^{1}$ & No COPD $(n=993)$ & p-value ${ }^{2}$ & p-value ${ }^{3}$ \\
\hline \multirow[t]{2}{*}{ Gender } & Men & 12.3 & & 6.9 & & 0.002 \\
\hline & Women & 9.1 & 0.109 & 4.6 & 0.138 & 0.008 \\
\hline \multirow[t]{6}{*}{ Age group, born } & -1920 & 32.7 & & 15.9 & & 0.003 \\
\hline & $1921-30$ & 18.4 & & 9.6 & & 0.030 \\
\hline & $1931-40$ & 9.1 & & 4.7 & & 0.020 \\
\hline & $1941-50$ & 3.0 & & 3.2 & & 0.883 \\
\hline & $1951-60$ & 2.8 & & 0 & & \\
\hline & $1961-$ & 0 & & 0 & & \\
\hline \multirow[t]{3}{*}{ Smoking } & Non smoker & 8.3 & & 5.3 & & 0.125 \\
\hline & Ex smoker & 12.2 & & 6.7 & & 0.008 \\
\hline & Smoker & 11.3 & 0.314 & 4.8 & 0.617 & 0.036 \\
\hline \multirow[t]{4}{*}{$\mathrm{BMI}$} & $<20$ & 25.6 & & 25.0 & & 0.960 \\
\hline & $20-<25$ & 9.9 & & 6.8 & & 0.131 \\
\hline & $25-<30$ & 9.6 & & 4.8 & & 0.006 \\
\hline & $\geq 30$ & 12.5 & 0.016 & 4.3 & 0.004 & 0.009 \\
\hline \multirow[t]{2}{*}{ Heart disease } & No & 9.1 & & 4.5 & & $<0.001$ \\
\hline & Yes & 19.6 & $<0.001$ & 12.9 & $<0.001$ & 0.102 \\
\hline
\end{tabular}

${ }^{1}$ Comparing within each category among subjects with COPD

${ }^{2}$ Comparing within each category among controls (no COPD)

${ }^{3}$ Comparing COPD and controls (no COPD) by each variable

\section{Discussion}

The strength and newsworthy of the current study is the up-to date report on the impact of COPD on mortality. The identification of the study population and the observation time took place during the twenty first century when treatment for COPD as well as cardiovascular disease was recommended according to modern and current guidelines. Further, the distribution of disease severity among subjects with COPD in the cohort was representative for what has been reported for the general population, comprising of more than $90 \%$ of patients in GOLD stages I and II [4]. COPD was a significant risk factor of increased mortality in this topical epidemiological context.

Table 3 Risk factors for death expressed as Hazard Ratio (HR) and 95\% Confidence Interval (CI) including the covariates age, time since recruitment, gender, smoking habits, COPD and heart disease

\begin{tabular}{llll}
\hline Variable & HR & $\mathbf{9 5 \% ~ C l}$ & p-value \\
\hline Age $^{1}$ & 1.09 & $1.07-1.11$ & $<0.001$ \\
Time since recruitment $^{1}$ & 1.03 & $0.95-1.12$ & 0.504 \\
Gender $^{2}$ & 1.43 & $1.02-2.00$ & 0.040 \\
Ex-smoker $^{3}$ & 1.29 & $0.87-1.92$ & 0.203 \\
Smoker $^{3}$ & 2.01 & $1.27-3.19$ & 0.003 \\
Heart disease $^{4}$ & 1.42 & $1.00-2.01$ & 0.051 \\
COPD $^{4}$ & 1.77 & $1.26-2.49$ & 0.001
\end{tabular}

${ }^{1}$ One unit change represents one year

${ }^{2}$ Reference group: female gender

${ }^{3}$ Reference group: non smoker

${ }^{4}$ Reference group: not reporting heart-disease respectively non-COPD
There are only a few previously published population based studies on mortality in subjects with COPD defined according to currently accepted spirometric criteria $[7-9,19]$. As referred to in the introduction, these study populations were recruited during the nineteenseventies and eighties. The mortality data in these studies

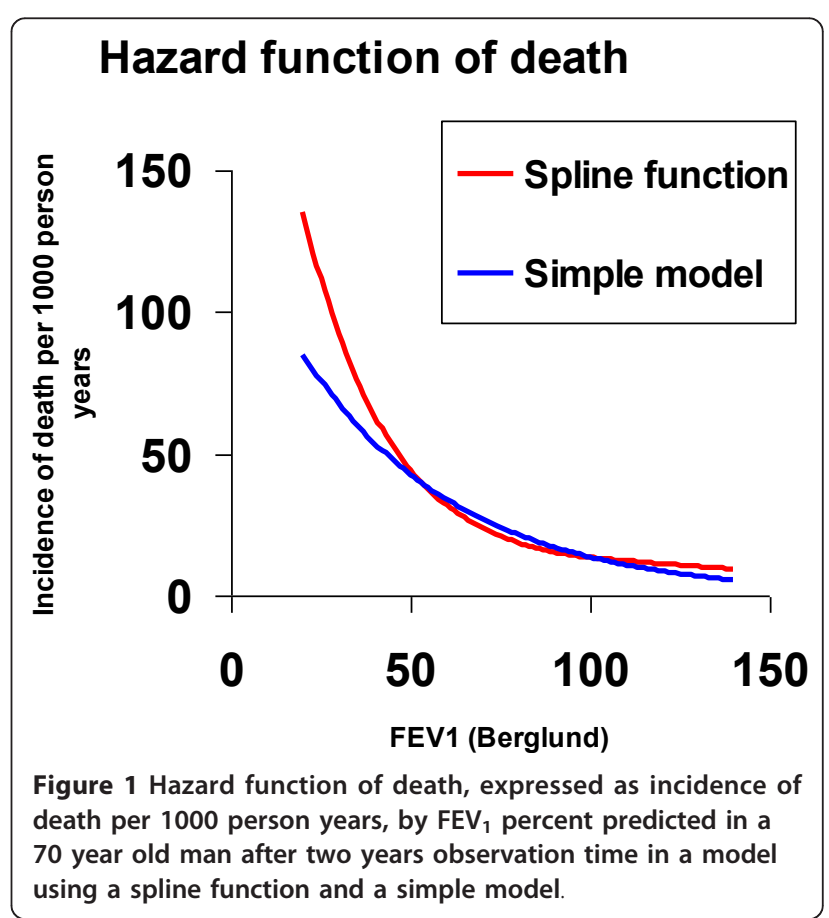


Table 4 Risk factors for death expressed as Hazard Ratio (HR) and $95 \%$ Confidence Interval (Cl), including the covariates age, time since recruitment, gender, heart

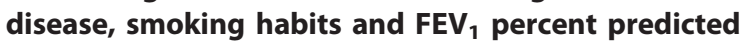

\begin{tabular}{llll}
\hline Variable & HR & $\mathbf{9 5 \% ~ C l}$ & p-value \\
\hline Age $^{1}$ & 1.09 & $1.07-1.11$ & $<0.001$ \\
Time since recruitment $^{1}$ & 1.03 & $0.95-1.12$ & 0.478 \\
Gender $^{2}$ & 1.45 & $1.03-2.03$ & 0.034 \\
Ex-smoker $^{3}$ & 1.26 & $0.85-1.86$ & 0.259 \\
Smoker $^{3}$ & 1.91 & $1.21-2.99$ & 0.005 \\
Heart disease $^{4}$ & 1.36 & $0.96-1.93$ & 0.084 \\
FEV $_{1}$ percent predicted $^{5}$ & 0.98 & $0.97-0.99$ & $<0.001$ \\
\hline
\end{tabular}

${ }^{1}$ One unit change represents one year

${ }^{2}$ Reference group: female gender

${ }^{3}$ Reference group: non-smoker

${ }^{4}$ Reference group: not reporting heart-disease

${ }^{5}$ The unit change represent one percent unit

were based on long term follow-ups from about ten years to more than twenty years, thus a healthy survivor effect must be taken into account when evaluating these data. Further, updated guidelines during the last decade for treatment of not only COPD, but also cardiovascular disease, have improved the prognosis compared to thirty years ago. Consequently, the starting point, the time and the length of the observation time are of importance when evaluating and comparing mortality data not only in COPD but also other diseases. There are mortality data collected in two large clinical trials started during the nineties with an observation time over three and four years respectively, the TORCH and the UPLIFT studies. The all-cause mortality reported from the TORCH-study was $14.3 \%$ [20] in a population with moderate- to severe COPD (FEV $1<60$ percent of predicted). In the UPLIFTstudy [21] subjects with a post-bronchodilator $\mathrm{FEV}_{1}<70$ percent of predicted were included, and the crude mortality in the total population was $15.4 \%$ at the end of the treatment period. After the approximately four year's observation time, similar to the UPLIFT, the mortality was $10.9 \%$ among subjects with in COPD in our study. However, the UPLIFT-cohort had a lower baseline mean $\mathrm{FEV}_{1}$ compared with our study, further, as most clinical studies the UPLIFT-study included a selected population with regard not only to lung function but also to other factors such as age and co-morbidity. Further, in a 13year follow-up of the ISOLDE study [22], the mortality was $56 \%$ in the study population including subjects with moderate- to severe COPD.

The reported mortality in this study can be considered up-to-date as both the identification of the study population and the observation time took place after the turn of the century, where modern and current guidelines for treatment have been well established in Sweden. Subjects with COPD in the cohort are considered representative for the general population with regard to distribution by disease severity [4]. There are, to the best of our knowledge, no other published similar studies. Further strengths of the study are the large size of the COPDpopulation, comparable to that of the NHANES I [7], the accuracy of mortality data and that there was no loss of follow-up. However, possible limitations are the comparatively short time of follow up and that information on heart disease was self-reported and not collected from medical records. Another limitation is that the classification of COPD was strictly made by spirometric criteria without regard to respiratory symptoms. This has to be considered when interpreting the data, as respiratory symptoms are known to affect the prognosis in mild/ moderate COPD [23]. Further, the non-COPD population did also include subjects with restrictive lung function impairment, even though the ability for a dynamic spirometry to identify restrictive lung function can be questioned. The reasons for a restrictive pattern on dynamic spirometry are highly heterogeneous and reflect different underlying disorders as idiopathic pulmonary fibrosis, thoracic deformities, obesity, pleural effusion, cardiac insufficiency and neuromuscular diseases.

As expected, increasing age was the most prominent risk factor for death. Among all subjects born $<1940$, the proportion of deceased was significantly larger among subjects with COPD. The use of a fixed ratio to define airway obstruction, $\mathrm{FEV}_{1} / \mathrm{FVC}<0.70$, has been discussed with regard to identifying clinically relevant COPD among elderly [24], but the results from our study indicate that the fixed ratio identifies a population with significantly increased mortality also among subjects older than 80 years. There is a recent report on 5-year mortality among subjects aged $>65$ years, where COPD according to GOLD was not associated with increased mortality among those older then 75 years [25]. However, the study population was recruited was from an out patient clinic, and can thus not be considered to reflect COPD in the general population.

When $\mathrm{FEV}_{1}$ was included in the multivariate analyse model, COPD was no longer a significant risk factor for death, but the level of $\mathrm{FEV}_{1}$, reflecting disease severity at recruitment, was related to mortality. Our data exemplify that a decrease in $\mathrm{FEV}_{1}$ in the range of 100 to 50 percent of predicted will continuously increase the risk for death, and further, illustrated by Figure 1, a dramatic increased risk for death occurs when $\mathrm{FEV}_{1}$ continues to decrease below 50 percent of predicted. It is well-known that tobacco exposure contributes to the development of both COPD and cardiovascular diseases, and cardiovascular death is the most common cause of death in the world. In a multivariate model heart disease was a significant risk factor for death just as COPD, age and male gender, however, when smoking habits were added to the model 
there was a slight change. Smoking roughly doubled the risk for death while male gender and reported heart disease each increased the risk on a similar level, approximately $40 \%$, even though heart disease did not reach statistical significance as a risk factor. Impaired lung function is a known risk factor for death $[10,11]$ and according to our results the risk for death in subjects with COPD, when adjusted for confounders including presence of heart disease, was increased by about $75 \%$ compared to in subjects without COPD. Maybe the impact of current treatment guidelines of cardiovascular disease has reduced mortality contributing to the borderline significance of heart disease as a risk factor while we found COPD and impaired lung function still being strong and significant risk factors for death.

Besides smoking, BMI is a known prognostic factor in COPD, and increased loss of weight is associated with a higher mortality in COPD $[26,27]$. In this study BMI could not predict mortality; however, longitudinal data on weight loss were not included. An important message is also the benefit of smoking cessation, i.e. being an exsmoker did not differ significantly from non-smokers with regard to risk for death, while current smoking roughly doubled the risk for death. According to a 9-year follow-up from the ECRHS non-smoking non-symptomatic young adults with mild/moderate COPD do not have worse outcome than subjects without COPD [23]. Further follow-up of our cohort will give us corresponding data from middle aged and elderly subjects with mild/moderate COPD. There was surprisingly no significant difference in prevalence of heart disease in subjects with and without COPD, however, the dominance of GOLD stage I and II in the COPD-cohort might contribute to this finding.

\section{Conclusions}

In this recently identified cohort, where COPD was mostly represented by GOLD stages I \& II, COPD, age and current smoking were the strongest risk factors for death. Male gender and reported heart disease were also, and on a similar level, associated to an increased risk for death, even though heart disease did not reach statistical significance. The results further indicate that not only COPD but also impaired lung function, expressed as level of $\mathrm{FEV}_{1}$, is a significant risk factor for death independent of confounders as age, gender, smoking habits and heart disease.

\footnotetext{
Acknowledgements

Main funding has been granted from the Swedish Heart-Lung Foundation, the Northern Sweden Regional Health Authorities and Umeå University. The Swedish Research Council has supported the management of the OLIN studies large data bases. Financial support was obtained from GlaxoSmithKline R\&D, World Wide Epidemiology department. Additional support has been given by the county council in the county of Norrbotten.
}

The authors thank Professor Anders Oden for statistical advice and analyses The authors also thank the research assistants RSN Ann-Christin Jonsson, RSN Sigrid Sundberg and MSc Linnea Hedman for collecting the data, BA Ola Bernhoff for work with creating the data base of the study and Viktor Johansson for computerising the data. Further, the late associate professor MD PhD Staffan Andersson and MD PhD Håkan Forsberg are acknowledged for their contributions.

\section{Author details}

${ }^{1}$ Department of Public Health and Clinical Medicine, Division of Medicine, Umeå University, SE-901 85 Umeå, Sweden. ${ }^{2}$ The OLIN studies and Division of Respiratory Medicine \& Allergy, Sunderby Hospital, SE-971 80 Luleå, Sweden. ${ }^{3}$ Division of Respiratory Medicine \& Allergy, Sunderby Hospital, SE97180 Luleå, Sweden. ${ }^{4}$ WorldWide Epidemiology, GlaxoSmithKline R\&D, Stockley Park, Uxbridge, Middlesex, UB11 1BT, UK. ${ }^{5}$ Department of Public Health and Clinical Medicine, Division of Occupational and Environmental Medicine, Umeå University, Umeå, SE-901 85 Sweden. ' Department of Internal Medicine/Krefting Research Centre, Sahlgrenska Academy, University of Gothenburg, SE-405 30 Gothenburg, Sweden.

\section{Authors' contributions}

$\mathrm{AL}$ designed the study, performed the statistical analyses, drafted and revised the manuscript. $L G L$ and $H M$ contributed to the paper by interpretation of data and critically revision of the manuscript. ER participated in the design of the study, and contributed to the paper by interpretation of data and critically revision of the manuscript. BL designed the study, drafted the manuscript, contributed to the paper by interpretation of data and critically revision of the manuscript.

All authors have read and approved the final manuscript.

\section{Competing interests}

The authors declare that they have no competing interests. Hana Muellerova is an employee of GlaxoSmithKline, R\&D, a producer of pharmaceuticals and owns shares and stock options of GlaxoSmithKline plc. The authors alone are responsible for the content and writing of the paper.

Received: 3 April 2011 Accepted: 9 January 2012

Published: 9 January 2012

\section{References}

1. Mathers CD, Loncar D: Updated projections of global mortality and burden of disease, 2002-2030: data sources, methods and results.[http:// www.who.int/healthinfo/statistics/bodprojectionspaper.pdf].

2. Halbert RJ, Isonaka S, George D, Iqbal A: Interpreting COPD prevalence estimates. What is the true burden of disease? Chest 2003, 123:1684-92.

3. Lundbäck $B$, Lindberg $A$, Lindstrom $M$, Rönmark $E$, Jonsson $A C$, Jonsson $E$, Larsson LG, Andersson S, Sandström T, Larsson K: Not 15 but $50 \%$ of smokers develop COPD?-Report from the Obstructive Lung Disease in Northern Sweden Studies. Respir Med 2003, 97(2):115-22.

4. Lindberg A, Bjerg A, Rönmark E, Larsson LG, Lundbäck B: Prevalence and underdiagnosis of COPD by disease severity and the attributable fraction of smoking Report from the Obstructive Lung Disease in Northern Sweden Studies. Respir Med 2006, 100(2):264-72.

5. Siafakas NM, Vermeire P, Pride NB, Paoletti P, Gibson J, Howard P, Yernault JC, Decramer M, Higenbottam T, Postma DS: ERS Consensus Statement. Optimal assessment and management of chronic obstructive pulmonary disease (COPD). Eur Respir J 1995, 8:1398-1420.

6. Lindström $M$, Jönsson $E$, Larsson $K$, Lundbäck B: Underdiagnosis of chronic obstructive pulmonary disease in Northern Sweden. Int J Tuberc Lung Dis 2001, 6(1):74-84

7. Mannino DM, Buist AS, Petty TL, Enright PL, Redd SC: Lung function and mortality in the United States: data from the First National Health and Nutrition Examination Survey follow up study. Thorax 2003, 58:388-93.

8. Ekberg-Aronsson M, Pehrson K, Nilsson J-Å, Nilsson PM, Löfdahl C-G: Mortality in GOLD stages of COPD and its dependence on symptoms of chronic bronchitis. Respir Research 2005, 6:98.

9. Lundbäck B, Eriksson B, Lindberg A, Ekerljung L, Muellerova H, Larsson L-G, Rönmark E: A 20-Year Follow-Up of a Population Study-Based COPD Cohort - Report from the Obstructive Lung Disease in Northern Sweden Studies. COPD: Journal of Chronic Obstructive Pulmonary Disease 2009, 6:263-271 
10. Ryan G, Knuiman MW, Divitini ML, James A, Musk AW, Bartholomew HC Decline in lung function and mortality; the Busselton Health Study. J Epidemiol Community Health 1999, 53(4):230-4.

11. Sunyer J, Ulrik CS: Level of $\mathrm{FEV}_{1}$ as a predictor of all-cause and cardiovascular mor-tality: an effect beyond smoking and physical fitness? Eur Respir J 2005, 25(4):587-8.

12. Sin DD, Wu L, Man SF: The relationship between reduced lung function and cardiovascular motality: a population-based study and a systematic review of the literature. Chest 2005, 127(6):1952-9.

13. Lundbäck B, Nyström L, Rosenhall L, Stjernberg N: Obstructive lung disease in northern Sweden: respiratory symptoms assessed in a postal review. Eur Respir J 1991, 4(3):257-66.

14. Lindström M, Kotaniemi J, Jönsson E, Lundbäck B: Smoking, respiratory symptoms and diseases - a comparative study between N Northern Sweden and Northern Finland - Report from the FinEsS study. Chest 2001, 119:852-61.

15. Lindberg A, Lundbäck B: The OLIN COPD study. Design, the first year participation and mortality. Clin Respir J 2008, 2:64-71.

16. [http://www.goldcopd.com].

17. American Thoracic Society: Standardization of spirometry, 1994 update. Am J Respir Crit Care Med 1995, 152(3):1107-36.

18. Berglund E, Birath G, Bjure J, Grimby G, Kjellmer I, Sandqvist L, Söderholm B: Spirometric studies in normal subjects, Forced expirograms in subjects between 7 and 70 years of age. Acta Med Scand 1963, 173:185-92.

19. Mannino D, Doherty D, Buist A: Global Initiative on Obstructive Lung Disease (GOLD) classification of lung disease and mortality: findings from the Atherosclerosis Risk in Communities (ARIC) study. Respir Med 2006, 100:115-22.

20. Calverley P, Anderson J, Celli B, Ferguson G, Jenkins C, Jones P, Yates J, Vestbo J: Salmeterol and fluticasone propionate and survival in chronic obstructive pulmonary disease. N Eng J Med 2007, 356:775-89.

21. Celli B, Decramer M, Kesten S, Liu D, Mehra S, Tashkin DP: UPLIFT study Investigators. Mortality in the 4-year trial of tiotropium (UPLIFT) in patients with chronic obstructive pulmonary disease. AJRCCM 2009, 180(10):948-55.

22. Bale G, Nartinez-Camblor P, Burge PS, Soriano JB: Long-term mortality follow-up of the ISOLDE participants: causes of death during 13 years after trial completion. Respir Med 2008, 102(10):1468-72.

23. De Marco R, Accordini S, Anto J, Gislason T, Heinrich J, Janson C, Jarvis D, Kunzli N, Leynaert B, Marcon A, Sunyer J, Svanes C, Wjst M, Burney P: Longterm outcomes in mild/moderate chronic obstructive pulmonary disease in the European Community Respiratory Health Survey. AJRCCM 2009, 108:956-963.

24. Hardie JA, Buist AS, Vollmer WM, Ellingsen I, Bakke PS, Morkve O: Risk of over-diagnosis of COPD in asymptomatic elderly never-smokers. Eur Respir J 2002, 20(5):1117-1122.

25. Pedone C, Scarlata S, Sorino C, Forastiere F, Bellia V, Antonelli-Incalzi R: Does mild COPD affect prognosis in the elderly? Pulmonary Medicine 2010, 10:35[http://www.biomedcentral.com/1471-2466/10/35].

26. Prescott $\mathrm{E}$, Almdal T, Mikkelsen $\mathrm{KL}$, Tofteng $\mathrm{CL}$, Vestbo J, Lange P: Prognostic value of weight change in chronic obstrctive pulmonary disease; results from the Copenhagen City Heart Study. Eur Respir J 2002, 20(3):539-44.

27. Hallin R, Gudmundsson G, Suppli Ulrik C, Nieminen MM, Gislason T, Lindberg E, Brøndum E, Aine T, Bakke P, Jansson C: Nutritional status and long-term mortality in hospitalised patients with chronic obstructive pulmonary disease (COPD). Respir Med 2007, 101(9):1954-60.

\section{Pre-publication history}

The pre-publication history for this paper can be accessed here: http://www.biomedcentral.com/1471-2466/12/1/prepub

doi:10.1186/1471-2466-12-1

Cite this article as: Lindberg et al:: Up-to-date on mortality in COPD report from the OLIN COPD study. BMC Pulmonary Medicine 2012 12:1.

\section{Submit your next manuscript to BioMed Central and take full advantage of:}

- Convenient online submission

- Thorough peer review

- No space constraints or color figure charges

- Immediate publication on acceptance

- Inclusion in PubMed, CAS, Scopus and Google Scholar

- Research which is freely available for redistribution

Submit your manuscript at www.biomedcentral.com/submit
Biomed Central 